\title{
The Problem of False Language Awareness
}

The paper opens with a discussion of the status of grammar rules in language awareness (LA) approaches where learners are encouraged to notice and reflect on regularities in the language. In this context, rules are post-fact descriptions of patterns noticed. The priority afforded discovery of patterns is linked in this paper to cognitivist views of learning (McClelland \& Rumelhart 1986; Anderson, 1983 in Cook 1993).

The paper then goes on to discuss the accuracy of rules transmitted in EFL classrooms. It is argued that teachers' awareness of the language is sometimes misinformed and that in addition half-truths may be presented to learners for the sake of simplifying a complex reality. This has the potential to cause misconceptions, i.e. false awareness, among learners. Data from three different studies (Svalberg 1997 and 1998b, Svalberg \& Hjh Fatimah 1998) are presented to demonstrate some misconceptions held by learners which may have been caused or reinforced by instruction. Such false awareness is potentially a serious problem as it could hinder further progress in the language. The paper closes with a brief discussion of what we might do to avoid false awareness being propagated in the EFL classroom.

\section{INTRODUCTION}

This paper addresses the issue of false awareness, i.e. misconceptions held by teachers and/or learners, in the area of grammar, but the main points may well be applicable to awareness in other areas of language ${ }^{1}$. The distinction sometimes made between 'consciousness' and 'awareness' (James 1992) will be ignored and the term 'consciousness raising' (CR) will sometimes be used for the process by which a state of relatively higher language awareness (LA) might be achieved.

The fact that LA implies conscious reflection on the language invites a comparison with traditional methods of teaching. One important difference between a LA approach and traditional 
grammar instruction is the role played by rules. I will distinguish between two different types of rules: what I call 'language manual rules' and 'language awareness rules'. By the former I mean a set of rules that the learner memorizes from a book or the white board and, if $\mathrm{s} / \mathrm{he}$ is a successful learner, learns to apply. The rules are imposed 'from above' by experts such as teachers and grammarians. It is questionable how much use language manual rules are to the learner (Borg 1996).

In the ideal case, the role of rules in a LA approach is not as "a body of externally, objectively defined knowledge to be studied" (Borg 1996, p.119) but rather as after-the-fact descriptions of linguistic patterns that the learner has observed. One advantage of the latter is that it can help remind the learner of a more complex and subtle linguistic reality than is easily contained in the words of a rule. It is important for this linguistic reality to be one that the learner has discovered and therefore has personal, conscious experience of.

The nature of grammar rules has been debated in the last few years, partly because of work in cognitive frameworks (see discussion of Anderson's ACT in Cook 1993, pp. 246-250; Ellis 1994, pp.403-408 on connectionism). According to connectionists (e.g. McClelland \& Rumelhart 1986), the language learning process does not consist of learning rules and how to apply them. A better description of the process, according to Mitchell \& Myles (1998, p.82), is that learners register associative patterns in the language which then become reinforced with use. The reinforcement of the associative patterns takes the form of a strengthening of neurological networks of connections.

An example of an observation which might become a rule in a learner's interlanguage is 'people use /d/ on verbs when they talk about the past'. Such a simple observation would need to be followed by other observations in order for the rule to be expanded and refined. How such a 
rule should best be described is beyond the scope of this paper (but c.f. for example 'production rules', Anderson 1983 in Cook 1993, p.249).

Because they encourage the discovery of patterns, LA approaches may prove to be a more effective way to help learners progress in a language. For the same reason, the potential to mislead and misinform is perhaps greater than ever and the accuracy of grammar rules (as descriptions of patterns) is vitally important. If learning a language does not mean learning to apply its rules but rather re-creating the rules by recognizing patterns, then we had better make sure that the patterns we help students discover are the right ones.

The term 'awareness' in LA implies that we make learners aware of facts about the language. The question raised here is to what extent we know the facts. That misconceptions and half-truths are prevalent in EFL grammar instruction is backed up by some of my own research findings (see below). Lock and Tsui (2000: 19), apparently share this concern as one of the aims of their electronic grammar database for teachers in Hongkong is "to explicitly address common misconceptions and potentially misleading half-truths". It would not be surprising then if instruction sometimes contributes to false language awareness.

Below, a few examples of false awareness exhibited by learners of English will be discussed. The ones chosen are likely to have been fostered or at least reinforced by instruction. There are, unfortunately, many ways in which misconceptions can be transmitted. Four potential sources will be exemplified: 1) misleading factual information, 2) misleading terminology 3) misleading illustrations and 4) misleading contexts. The possible implications of false awareness will then be discussed and some suggestions made as to what can be done to avoid false awareness being propagated. 


\section{MisCONCEPTIONS AND HALF-TRUTHS}

One half-truth propagated through instruction is that English has three tenses: past, present and future. In fact, English has two tenses only: past and present (or non-past) (Reichenbach 1957, Comrie 1985, Svalberg 1986, 1991, 1995). While there are, as we all know, many ways of expressing future events in English, there are good reasons for not considering that there is a future tense as such. One is that there is no inflectional future form. Another is that all the forms that can refer to future time frequently have other meanings as well. From a teaching perspective, presenting future as a tense on a par with past and present has the potential to obscure patterns of tense use in English, e.g. tense agreement.

The relationship of verb forms to tense meanings is arguably one of the most important associative patterns in the English grammar. It can be represented as follows:

Figure 1 The English tense system (adapted from Svalberg 1991)

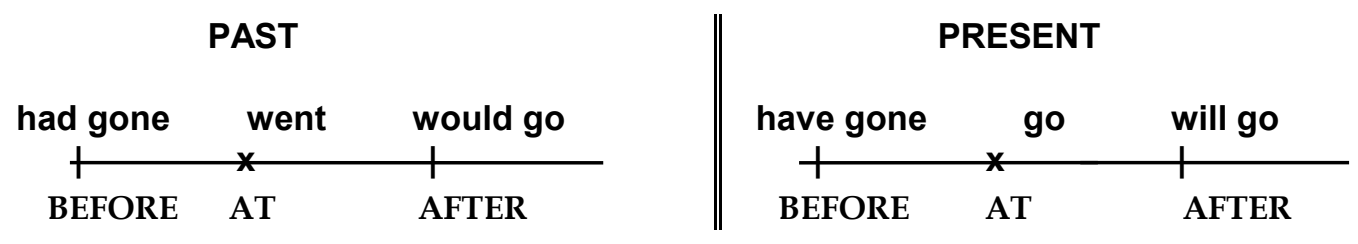

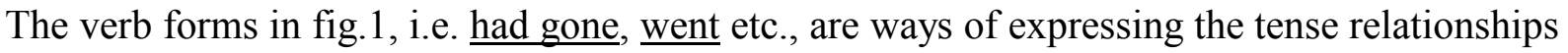
in the figure. Other forms can also be used, e.g. past and present progressive for events at or after past or present, but the relationship is not random; present progressive cannot be used to mean an event before present, for example.

The obscuring of the concept of past and present reference time (the ' $\mathrm{x}$ ' points in fig.1) is a major weakness in most teaching of tense. The importance of learning to recognize past and 
present is that (when we refer to time) all past tense verb forms relate events to a past reference time only (left half of fig.1) and all present tense forms relate events to the speaker's present (right half of fig.1). Somewhat simplified, one can say that tense agreement consists of learning to use past tense when the reference time is past and present tense when the reference time is present (see Svalberg 1991, 1995).

The different verb forms refer to events before, at or after either past or present. Perfect forms, for example, always refer to events before either past (past perfect) or present (present perfect). Forms with would are multifunctional and are one of several ways of referring to events after the past as in for example $\underline{\mathrm{I} \text { knew she would be } 18 \text { by then. }}$

In summary, the concept of past and present reference time can help highlight patterns of language use which are otherwise difficult for learners to discern. Such patterns - which the learner can subsequently translate into rules - include which verb forms encode which of the meanings in Fig.1, i.e. patterns of tense agreement and sequencing of events.

Part of the problem with teaching the use of verb forms is the term 'tense'. In its technical sense, 'tense' means reference time, i.e. past or present, as shown above. It is, however, frequently used in a more everyday sense to mean 'verb form'. Thus one can see references to 'progressive tense', 'perfect tense', 'past progressive tense', 'present progressive tense' and so on. A learner could be excused for feeling totally bewildered. If instead we used 'tense' only to refer to past or present reference time, we would be better placed to put across the correct associative patterns of both English tense and aspect. The term 'aspect' can be used for progressive, perfect and simple ${ }^{2}$, though to some classroom practitioners it may seem too 'technical'. Most of the time, the problem can be avoided by using nothing in place of the word 'tense', i.e. 'the progressive' rather than the 
misleading usage 'the progressive tense'. This would involve EFL teachers examining and perhaps modifying their own language awareness, but it would seem an effort worth making.

The observant reader may object at this point that so called 'past' verb forms are often used for present events, e.g. to mark politeness or tentativeness as in I was wondering if you wanted to

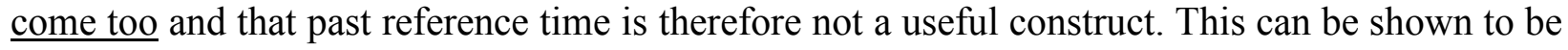
an untenable position on theoretical grounds (Comrie 1985; Svalberg 1991) and, from a teaching/learning perspective, it is precisely because the grammar is far from transparent that the basic use of past verb forms for past time needs to be highlighted first. One can then build on that when teaching other non-time related uses of past (see discussion of 'distance' in Svalberg 1991; 1995).

Another misconception often encountered among students as well as teachers is the idea that the present perfect means that the event happened recently. That this is not so can easily be demonstrated:

\section{People have always adorned their bodies in different ways.}

2. I've been to Paris. What an experience! Must be nearly thirty years ago now.

In neither of the two examples is the event recent. The fact that the Present Perfect is frequently used for recent events is because such events are more frequently mentioned and more likely to have 'current relevance' than distant events. Nevertheless, it is not recentness but 'current relevance', sometimes in the form of results or experiences, which is conveyed by the Present Perfect $^{3}$. In some of the more recent EFL text books this is very clearly put across but others still overemphasize the importance of the collocation 'just + present perfect'. The context can then become misleading by being over-represented in the input. 
That instruction may have a role to play in the misperception of present perfect was indicated by the results of a meaning perceptions test (Svalberg 1997 and 'forthcoming'). As the test is not the main subject of this paper, most of the information regarding it is to be found in Appendix 1, but some is required here: Each test item contained an underlined verb form embedded in a minimum of context (see 3 and 4 below); the subjects were 43 native and 66 non-native speakers of English, the latter Malay L1 speakers in Brunei who, based on an earlier test result, were divided into a top group $(\mathrm{N}=32)$ and a bottom group $(\mathrm{N}=34)$. For each item, the subjects were asked to choose a maximum of three meanings in a multiple choice matrix to indicate the meaning of the underlined words.

The meaning perceptions test confirmed that time depth played an important role in the learners' perceptions of past and present perfect, though not entirely as expected. The test items containing present perfect were the following:

\section{3. the students have written the essays}

4. the girls have arrived

The multiple choice matrix for these items included the meanings 'a long time ago' and 'a short time ago'. The table below represents the replies to these options for items 3 and 4 taken together and shows that more non-native than native speakers associated present perfect with time depth, especially recent time. 
Table 1 Proportion of subjects who indicated that present perfect means 'a short/long time ago'

\begin{tabular}{|c|c|c|}
\hline & 'a short time ago' & 'a long time ago' \\
\hline Native Speakers & $23.5 \%$ & $1.5 \%$ \\
\hline Top Group & $50.5 \%$ & $20.5 \%$ \\
\hline Bottom Group & $47 \%$ & $7.5 \%$ \\
\hline
\end{tabular}

The top \& bottom groups are non-native speakers of English.

Because of the range of possible contexts for the test items, there were no right answers as such in the meaning perceptions test. What it aimed to measure was to what extent the non-native speakers deviated from the patterns of associations evident in the native speaker group.

About twice as many non-native speakers as native speakers felt that recentness was a salient meaning of the present perfect and perceptions in this regard did not become more native-like with higher proficiency. In addition, over $20 \%$ of the most proficient learners chose 'a long time ago'. The perception that time depth was involved was thus very prevalent among the non-native speakers. The figures, especially for the more proficient learners, indicate that it would be unhelpful to reinforce time depth notions in the classroom by an overemphasis on such contexts.

In a grammaticality judgement test taken by the same subjects (Svalberg 1998b; see also Appendix 1) another learner misconception to come to light was that Past Perfect could be used in the following context:

5. As Ms Edwards had broken her leg, class is cancelled today.

Nearly $66 \%$ of the top learners and $73.5 \%$ of the bottom learners felt that this was grammatical (Svalberg 1998b). The reason this sentence is in fact ungrammatical is that the past 
perfect denotes an event before a past reference time (see fig.1) and no such past time can be retrieved. That learners would make this mistake is not surprising considering that past perfect is usually very late acquired, if at all (Bardovi-Harlig 1994). One way of 'making sense' of it, is to use it as a marker of completedness, regardless of tense, and this may be what the learners did in the grammaticality judgement test (Svalberg 1998b). The tense pattern of past and present reference times, displayed in fig.1, needs to be noticed first for learners to discover how past perfect is used in conjunction with tense agreement rules. This illustrates the importance of using the term 'tense' in a clarifying way and to highlight basic 'tense for time' patterns as suggested above.

There are other indications that instruction may be less than helpful. In the meaning perceptions test, learners also associated the past perfect more strongly with time depth than the native speakers did and this non-nativelike tendency became stronger as they became more proficient. The test items containing past perfect were:

\section{6. the girls had slept \\ 7. Kassim had opened the door}

The following table represents the replies to 6 and 7 taken together and shows the extent to which the different groups associated past perfect in these items with time depth:

Table 2 Proportion of subjects who indicated that Past Perfect means 'a short/long time ago'

\begin{tabular}{lll}
\hline \hline & "a short time ago" & "a long time ago" \\
\cline { 2 - 3 } Native Speakers & $19 \%$ & $5 \%$ \\
\hline \hline
\end{tabular}




\begin{tabular}{lll}
\hline \hline Top Group & $23.5 \%$ & $36 \%$ \\
Bottom Group & $23.5 \%$ & $16.5 \%$ \\
\hline \hline
\end{tabular}

The top \& bottom groups are non-native speakers of English.

The figures in table 2 show that as learners become more proficient they become more prone to perceiving past perfect as referring to events a long time ago. Though this may be true in a particular sentence, it is not generally true as demonstrated by the following exchange:

8. - What's the matter?

- Oh, I'm upset! I talked to Dave. I'd just told him I was preparing for this horrible inspection and then he asked me to type thirty pages for him!

I've

In the mini-dialogue, the present perfect have been stretches back further in time than the past perfect had told. This demonstrates that distance in time (time depth) is of no importance, i.e. it is not encoded, in the English tense system. What is important is sequence of events and whether events are related to the past or the present.

Misleading illustrations can reinforce this misconception. In the classroom, timelines are sometimes used in an attempt to clarify the use of the past perfect. The following is an unfortunate example:

Figure 2 A misleading illustration of the past perfect

had got into bed the phone rang NOW


In the sentence $\underline{I}$ had just got into bed when the phone rang the event in the past perfect is indeed further away from the present than the event in the past simple and so the representation in fig. 2 would seem quite adequate. The problem is the impression that past perfect generally encodes (or 'means') an event further away in time from the present than past simple. However, it is quite possible to have a past simple and a past perfect in the same text which do not stand in this out-of-sequence relationship to each other and where the past perfect does not denote an event further away in time than the past simple, just as (in 8 above) a past perfect event can be closer in time than a present perfect event. It is the inclusion of the present on the time line which creates the false impression of time depth.

To summarize, the past perfect says nothing about how long ago the event happened, only that it happened before another time in the past (fig.2). Classroom instruction which does not make the distinction between past and present reference time clear is therefore likely to contribute to difficulties in the acquisition of the past perfect. We will return to this when considering implications.

The discussion above has highlighted the possibility of leading learners astray by the misuse of terminology, illustrations and contexts. A narrow range of contexts can perpetuate another half-truth: that would means 'not a fact' or, 'unreality'. It is true, of course, that would is used in some non-factive contexts, e.g. conditionals. In text books it is often presented in highly speculative contexts such as if I won the lottery I would .... Except for polite expressions with

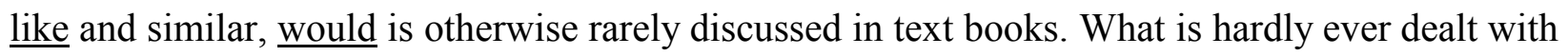
is would for past habit. In this use, would is factual as it describes an event that actually took 
place, e.g. My grandpa would have his tea under that tree. Unreality is thus not a meaning of would, but a feature of some of the contexts in which it is frequently found.

The findings from the meaning perceptions test confirm that unreality is a more salient meaning of would for learners than for native speakers and this misperception becomes more prevalent as learners become more proficient. There were six items containing would (see Appendix 1), an example being:

9. the girls would sleep

Among the options in the multiple choice matrix, were 'fact' and 'not a fact'.

Table 3, a summary of the responses to these options for the six items with would, shows that the learner subjects were more prone than the control group to associate would with the option 'not a fact': 
Table 3 Proportion of subjects who indicated that would means 'not a fact'

\begin{tabular}{ll}
\hline \hline Native Speakers & $5.7 \%$ \\
Top Group & $23.2 \%$ \\
Bottom Group & $11.2 \%$ \\
\hline \hline
\end{tabular}

The top \& bottom groups are non-native speakers of English.

As we saw above, it is true that would in certain contexts indicates a greater degree of unreality (or lesser degree of likelihood) than will and so one cannot say that the learners who chose 'not a fact' are 'wrong'. Rather, to the extent that they made this choice more often than the native speakers, their knowledge is skewed. The fact that the tendency, consistent across the six test items, became more marked as the subjects became more proficient makes it plausible that instruction, perhaps in the form of a misleading range of contexts, has played a part here.

The factual use of would was brought to my attention by some conversation data I also obtained in Brunei. A group of 5 Malay speaking learners and a group of 4 native English speakers were recorded having separate conversations in English, on the same topic and of roughly the same duration (Svalberg \& Hjh Fatimah 1998). The non-native speaker subjects were prospective EFL teachers. As far as fluency and vocabulary were concerned, they might have been classed as upper intermediate level. The native speakers, practising EFL teachers, used would 28 times, mostly for past habit. An example of this use from the native speakers' conversation is: and then I would also watch English programmes on TV which had Swedish subtitles. In contrast, the non-native speakers did not use would a single time. Their reluctance or inability to use the modal in the given factual context could be explained if they, like the subjects in the meaning perceptions test, perceived unreality as a salient meaning of would. 
In the Bruneian context, sociolinguistic factors, beyond the scope of the present paper (but see Svalberg $1998 \mathrm{~b}$ and 'forthcoming'), almost certainly contribute to the learners' skewed perception ${ }^{4}$ of would. Whatever the reasons, the highlighting of its use in a narrow range of nonfactive contexts to the virtual exclusion of other uses has the potential to reinforce rather than correct learners' false awareness.

\section{Implications}

It has been shown that learners have some misconceptions about English, which is not in itself surprising. The reason the particular misconceptions discussed above are noteworthy is that 1) they do not decrease with higher proficiency, instead they sometimes become more marked, 2) it is likely that instruction has contributed to the misconceptions.

It is also likely that further progress can be hampered by such false awareness. It can be assumed that the extent to which learners are able to expand and improve their command at time ' $t$ ' depends partly on the state of their knowledge at ' $t$ '. To explore the implications, one can think of language as an enormous and very complex puzzle. Each piece of a puzzle has a number of protruding portions which give it an awkward shape but which are essential if it is to connect with the surrounding pieces in the puzzle. If the piece is the wrong shape to start with or if the awkward bits are chopped off to make it tidier, then it won't fit into the puzzle and the puzzle cannot be completed. Each bit of language awareness then, has the potential to help or to hinder further progress. Simplifying or skewing the truth may be tantamount to 'chopping off the awkward bits' and one needs to be aware of this.

For the learners discussed above the piece of the puzzle containing would had the wrong shape, probably partly due to instruction. They felt quite strongly that would meant unreality. 
This, I would argue, could interfere with their acquisition of factive would for past habit, at least until a teacher (or real life misunderstanding) actively intervenes to correct their awareness.

Learners' attempts to make sense of the input they get will thus interact with their misconceptions. The persistence of the idea that perfect has something to do with time depth could indicate an attempt by the learners to construct their own interim tense system. The following is one possibility:

Figure 3 A possible, though inaccurate, interim English tense system:

$$
\begin{array}{c|c|c|c|}
\begin{array}{c}
\text { A long time } \\
\text { ago } \\
\text { had gone }
\end{array} & \begin{array}{c}
\text { General past } \\
\text { went }
\end{array} & \begin{array}{c}
\text { Recently } \\
\text { have gone }
\end{array} & \begin{array}{c}
\text { Present } \\
\text { go }
\end{array}
\end{array}
$$

This tense system is reminiscent of the misleading time line shown above (fig.2). As demonstrated in fig. 1 and example 8 (above) the perception of English tense displayed in fig. 3 is incorrect, but it is a plausible learner hypothesis. From a cognitive point of view, it would not be surprising or unnatural for learners to assume such a system. In many languages time depth is indeed the organizing principle, e.g. reportedly in the North-American Indian language Kiksht (Hymes 1975, discussed in Svalberg 1991):

Figure 4 A different kind of tense system: Kiksht (N. American Indian; data from Hymes 1975, adapted from Svalberg 1991)

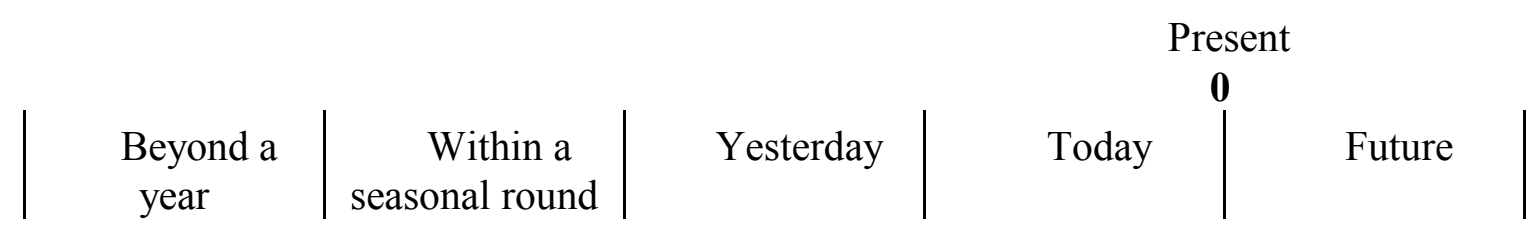


$\mid$ gal $\mid$ nig $\mid$ nal $\mid$ ig $\mid$ al $\mid$

In Kiksht, a verb with the suffix -nig denotes an event further away in time than a verb with -

nal, and events a long time ago are expressed by verbs ending in -gal. Time depth is a central notion in this tense system as in many others, e.g. in Bantu languages which have special 'narrative tenses' (Dahl 1985).

There does not seem to be any cognitive reason to assume, then, that learners will automatically hypothesize an English-type tense system. In addition, it is quite difficult to deduce from input how English tense works (Svalberg 1998a). Endings like -ed and -ing are used not only on verbs but also on adjectives (-ed, -ing) and nouns (-ing); past forms are used with present time reference and non-finite verbs can be difficult to distinguish from finite ones (e.g. past simple from past participle). The input learners get through instruction is therefore crucial. This is especially so for learners who either have time depth notions in their L1 verb system or learners who have tenseless L1, e.g. speakers of Chinese, Malay, Arabic.

\section{Conclusions}

It was argued in the introduction that LA rules are after-the-fact descriptions of patterns observed. It is however important to recognize that not all patterns which language aware learners, or indeed teachers, may notice in input will automatically lead to correct rules. Rules based on frequency can be misleading. Learners may, for example, notice that the correlation of recentness of events with the use of present perfect is quite high or that would is used in certain syntactic constructions which refer to unreal events. I have tried to show that accurate observations such as these are not necessarily sufficient. If other, complementary observations 
are not made which allow the rules to be expanded and modified, these observations could result in the creation of false awareness of the kind described in this paper.

It was argued above that false LA can in fact hinder further progress. One example was the strong association of would with unreality which is likely to impede or slow down the acquisition of would for past habitual events. The association of present and past perfect with time depth could potentially lead to an un-English interpretation of the whole tense system. It is hard to see, finally, how the past perfect could be acquired at all if the pattern of relationships between past verb forms and past and present reference time has not been acquired first.

To avoid spreading false LA, we - EFL teachers and other EFL professionals - need to do more to check our own awareness and improve and expand it constantly. As Borg (1994, p.63) states:

Teachers need to develop a disposition to constantly review their own beliefs about language, and to be open to the possibility that these may require modification.

This can be extended to language professionals generally, not just teachers - we are all learners.

A positive development is that increased research on authentic language, i.e. use of corpora, could mean great strides being made in the formulation of more accurate rules which would eventually benefit teachers and learners. New insights into English such as current views on tense and the use of articles (e.g. Master 1997) also need to be passed on to teachers on a regular basis, e.g. through in-service courses.

Despite what has been said about the importance of accurate rules, simplification for learners is sometimes unavoidable. There seems to be no reason to hide this fact. On the contrary, the 
incompleteness and temporariness of rules should be acknowledged (and can be indicated by the term 'rule of thumb'). To the extent that rules are 'LA rules', i.e. descriptions of learners' observations, they have the potential to expand and improve as the learner progresses.

What this paper has wanted to address is the assumption that the LA displayed by teachers and textbooks is unproblematic. I have tried to show that learners' awareness is sometimes false awareness quite likely to have been created or reinforced by instruction - misleading facts, terminology, illustrations and contexts - and that this can be a serious obstacle to further progress in the language. It has also been argued that in the LA classroom grammar rules should be seen as after-the-fact descriptions of patterns that learners notice in the course of the acquisition process, and that for these rules to be useful, they should coincide with the facts as encountered in authentic language. A solution to the false awareness problem has to start with EFL professionals improving and expanding our own language awareness. 


\section{Notes}

1. I am grateful to anonymous reviewers for helpful and incisive comments on this paper which was presented in an earlier version at the 5th International Conference of the Association for Language Awareness, 26-29 June 2000, University of Leicester.

2. In my analysis (Svalberg 1991) 'simple' is one of three aspects in English, rather than an unmarked choice, as simple verb forms can be shown to encode particular aspectual meanings distinct from either perfect or progressive.

3. I take the view that as far as English is concerned, it is not necessary to distinguish experiential and resultative as distinct categories of perfect use. They can usefully be subsumed under the umbrella term 'current relevance'.

4. Perceptions are 'skewed' from a Standard British English (STE) point of view though not necessarily from a local, non-standard perspective. It was assumed, however, that because of the instructional context the subjects' aim was to supply STE replies. In a similar context (Svalberg \& Hjh Fatimah 1998) the subjects claimed that their target had been 'good English', i.e. the officially sanctioned STE variety.

\section{REFERENCES}

Bardovi-Harlig, K. (1994) Reverse-Order Reports and the Acquisition of Tense: Beyond the principle of chronological order. Language Learning 44 (2), 243-282

Borg, S. (1994) Language Awareness as a methodology: Implications for teaching and teacher education. Language Awareness 3 (2), 61-72

Borg, S. (1996) Language pedagogy and linguistics. Language Awareness 5 (2), 118-124

Comrie, B. (1985) Tense. Cambridge: Cambridge University Press.

Cook, V. (1993) Linguistics and Second Language Acquisition. London: Macmillan

Dahl, Ö. (1985) Tense and Aspect Systems. Oxford: Basil Blackwell

Ellis, R. (1994) The Study of Second Language Acquisition. Oxford: Oxford University Press

Hymes, D. (1975) From Space to Time in Kiksht. International Journal of American Linguistics 41 (4), 313-29. 
James, C. (1992) Awareness, consciousness and language contrast. In C. Mair \& M. Markus. (eds) New Departures in Contrastive Linguistics. Proceedings of the conference held at Leopold-Franzens University of Innsbruck, Austria, 10 - 12 May 1991, Vol. II, 183-197

Lock, G. \& A. B. M. Tsui (2000) Customizing Linguistics: Developing an electronic grammar database for teachers. Language Awareness 9 (1), 17-33

Master, P. (1997) The English article system: Acquisition, function and pedagogy. System 25 (2), $215-232$

McClelland, J. \& Rumelhart, D. (1986) On learning the past tenses of English verbs. In McClelland, J. \& Rumelhart, D. (eds) Parallel Distributed Processing: explorations in the microstructure of cognition. Vol 2: Psychological and biological models. Cambridge MA: MIT Press, 216-271

Mitchell, R \& Myles, F. (1998) Second language learning theories. London: Arnold

Reichenbach H. (1957) The philosophy of space and time. New York: Dover Publications.

Svalberg, A. M-L. (1986) Teaching tense and aspect: a systematic approach. ELT Journal 40 (2), 136-145

Svalberg, A. M-L. (1991) A cognitive model of TMA systems; with special emphasis on English and Modern Greek. Ph.D. dissertation (Unpublished), Sydney University.

Svalberg, A. M-L. (1995) Meanings into pictures: Icons for teaching grammar. Language Awareness 4 (2), 65-88

Svalberg, A. M-L. (1997) The conceptualization of English tense and aspect by Malay speakers. Paper presented at the 31st IATEFL conference, Brighton 2-5 April, 1997

Svalberg, A. M-L. (1998a) Comprehensibility of input and the acquisition of grammar. Journal of Applied Linguistics 14, Thessaloniki, 71-88

Svalberg, A. M-L. (1998b) Nativization in Brunei English: Deviation vs. Standard. World Englishes 17 (3), $324-$ 344

Svalberg, A. M-L. (forthcoming) The understanding of 'would' by native and non-native speakers of English. Journal of Asia Pacific Communication.

Svalberg, A. M-L. \& Hjh Fatimah binti Hj Awg Chuchu. (1998) Are English and Malay worlds apart? The effect of typological distance on the learning of tense and aspect. International Journal of Applied Linguistics 8 (1), 2760 


\section{Appendix}

This appendix provides some information about the meaning perceptions test and the grammaticality judgement test referred to in the paper. The grammaticality judgement test is discussed in depth in Svalberg 1998b, the meaning perceptions test in Svalberg 1997 and Svalberg 'forthcoming'. Both tests were administered to the same subjects:

Table A.1 Subjects of the grammaticality judgement test and the meaning perceptions test.

\begin{tabular}{llll}
\hline \hline NS & NNS: & NNS: & NNS: \\
Control & Top Group & Middle Group & Bottom Group \\
\hline 43 subjects & 32 subjects & 40 subjects & 34 subjects \\
\hline \hline NS: Native speakers of English & NNS: Non-native speakers of English
\end{tabular}

The subjects were rank ordered for proficiency on the scores of a previous English Language test. The non-native speaker subjects were Malay speaking first year students at Universiti Brunei Darussalam. The native English speakers were second year students at Edith Cowan University in Perth. The middle group is not referred to in the present paper.

In the grammaticality judgement test (Svalberg 1998b), the test items had to be judged for grammaticality and, if judged to be unacceptable, the error had to be underlined. There were 20 items; 11 correct and 9 incorrect. All the infelicities were tense or aspect errors.

In the meaning perception test (Svalberg 1997 and 'forthcoming'), the test items had the following format: 
Figure A.1 An item in the meaning perceptions test.

15. the girls would sleep.

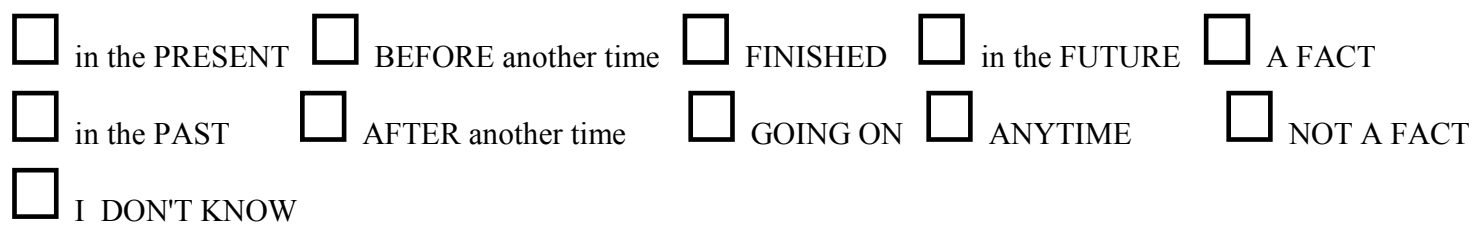

There were 32 items in all in this latter test, representing 16 different verb forms. In each item the verb group was underlined. Items which contained past or present perfect had a slightly different matrix in that 'in the future' and 'anytime' were replaced by 'a short time ago' and 'a long time ago'. Following piloting which explored different types of instructions, the subjects were instructed in Malay and English to choose a maximum of three options to show what the underlined words, i.e. the verb groups, meant.

The test items deliberately provided a minimal context, as can be seen in Fig.A.1. This may seem surprising as the full meaning of any verb, and modals in particular, are to a great extent a function of the context in which they appear. The purpose of the meaning perceptions test, however, was to find out what meanings were triggered by the verb forms per se and, especially, if there were differences in this respect between the native and non-native speaker subjects. An underlying assumption was that no matter how minimal or incomplete the string, the subjects would attempt to interpret it and in the process of doing so would activate or construct appropriate schemata. Any context provided would bias the interpretation process towards one meaning or another. It was therefore crucial to keep the context as minimal and as neutral as possible. On the other hand, presenting the verbs on their own, e.g. as verb forms in a list, was ruled out for a number of reasons and the simple arrangement shown in Fig.A.1, of subject + verb and, if required, object was chosen. In interpreting the verbs in these strings, the subjects were 
thus forced to provide their own wider contexts. As a consequence, there was no one 'correct answer' to each test item. Instead, replies were expected to be more or less 'native-like' depending on what schemata the subjects had been able to construct or access.

As far as the meaning perceptions test goes, the items referred to in this paper are the six test items containing would:

1. the girls would sleep

2. Kassim would open the door

3. the boys would be arriving

4. the student would be writing essays

5. the girls would have slept

6. Kassim would have opened the door

and the four items containing perfect forms shown in the body of the text. 